Nataša Petrović ${ }^{1}$, Miodrag Milenović ${ }^{1}$, Ivan Stoimirov ${ }^{1}$, Marija Milenković ${ }^{1}$, Zlatibor Lončar ${ }^{2}$

\title{
PROPUSTI U ZBRINJAVANJU POLITRAUMATIZOVANOG PACIJENTA
}

Sažetak: Previđene povrede su one povrede koje nisu dijagnostikovane u prvih 48-72 sata od prijema, odnosno u fazi stabilizacije povređenog pacijenta. To su obično povrede na koje se nije mislilo. Previđenim povredama ne smatraju se one povrede koje su namerno ostavljene za kasniju dijagnostiku da bi se najpre stabilizovale vitalne funkcije i uradile neophodne intervencije koje se ne mogu odlagati. Ovo podrazumeva nastavak dijagnostike, što se nekada ne uradi! Podaci o učestalosti previđenih povreda variraju, u referentnoj literaturi navodi se da je procenat ovakvih povreda i grešaka u zbrinjavanju 8-29\%.

Abdomen je u traumi obično „crna kutija”. Pregled abdomena je u svim protokolima za traumu jedna od vodećih procedura, ali nekada se zanemari ili izvođenje pregleda ili čak tumačenje pozitivnog rezultata! Povrede dijafragme se relativno često previđaju, naročito ako je otvor na dijafragmi mali.

Rana nadoknada predstavlja uvod u scenario neprepoznavanja tamponade srca. Tamponada srca obično odgovara na relativno mali nadoknadni volumen, stvarajući lažni utisak da je uzrok hipotenzije hipovolemija.

Fisure sternuma se često previđaju jer se ne uradi profilni snimak. Povrede sternuma su sumnjive na druge teške povrede!

Vrlo mladi, vrlo stari, imunodeficijentni pacijenti i trudnice su osobe sa specijalnim potrebama u lečenju traume.

Previđene povrede nose ozbiljan rizik po pacijenta i imaju veliki forenzički značaj, pa je ovo tema kojoj bi trebalo posvetiti više mesta u diskusijama u stručnoj javnosti.

Ključne reči: Propuštene povrede, politraumatizovan pacijent, najčešće greške

\section{Uvod}

Previđene povrede su one povrede koje nisu dijagnostikovane u prvih 48-72 sata od prijema, odnosno u fazi stabilizacije povređenog pacijenta. To su obično povrede na koje se nije mislilo. Previđenim povredama ne smatraju se one povrede koje su namerno

1 Nataša Petrović, Klinika za anesteziju Urgentni centar, Klinički centar Srbije

2 Klinika za hirurgiju, Urgentni centar, Klinički centar Srbije 
ostavljene za kasniju dijagnostiku da bi se najpre stabilizovale vitalne funkcije i uradile neophodne intervencije koje se ne mogu odlagati. ${ }^{1}$ Ovo podrazumeva nastavak dijagnostike, što se nekada ne uradi! Podaci o učestalosti previđenih povreda variraju, u referentnoj literaturi navodi se da je procenat ovakvih povreda i grešaka u zbrinjavanju 8-29\%. Treba napomenuti da je ovo tema o kojoj se nerado govori, te da je broj publikacija mali.

„Etiketiranje” pacijenata po dijagnozi sužava razmišljanje o mogućim povredama; na primer: „ubodna rana desne nadlaktice” često zadovolji dijagnostičku radoznalost iako možda postoji i neka druga povreda. ${ }^{2}$

\section{Najčešće greške prilikom prvog pregleda}

Greška je ne skinuti pacijenta prilikom pregleda, jer se mogu prevideti ozbiljne povrede.

Greška je ne uzeti detaljnu anamnezu od pacijenta ili pratnje. Posebno je potrebno naznačiti korišćenje beta blokatora, kardiotonika i antihipertenziva, antikoagulanata i aspirina (što može komplikovati kliničku sliku, ali i dati rizik od krvarenja posebno endokranijalnih).

Sprovođenje kliničkog pregleda bez pridržavanja protokola (značajni simptomi i znaci mogu biti previđeni - zato je neophodno koristiti protokole!). ${ }^{3}$

\section{Disajni put - najčešće greške}

- Uvođenje laringoskopa i intubacija u prisustvu refleksnog laringealnog spazma (izaziva povraćanje i aspiraciju sadržaja);

- traheotomija u urgentnim stanjima (čak i kad je izvode iskusni hirurzi, ona traje nekoliko minuta, za razliku od metode izbora - krikotiroidektomije).

- Sedacija pri endotrahealnoj intubaciji kod pacijenata sa obimnim hematomima vratne regije, ako ne prisustvuje hirurg, spreman da uradi kriktiroidektomiju. Problem predstavlja nemogućnost vizuelizacije vazdušnog puta zbog hematoma. Samim tim je intubacija jako otežana, što može biti katastrofalno kod sediranih pacijenata sa ugroženim disanjem).

- Potcenjena opasnost od opstrukcije vazdušnih puteva. Pogoršanje može nastati naglo i brzo - poželjna rana intubacija ili hirurški pristup disajnom putu ${ }^{1,4}$,

Teška dilatacija želuca nastala gutanjem vazduha može uzrokovati respiratorne poteškoće ili komplikovati pregled abdomena. Plasirati nazogastričnu sondu u slučajevima kada je to indikovano.

\section{Greške u toku prijema pacijenta}

Nikad ne upućivati pacijenta koji je povrede zadobio u saobraćajnom udesu ili padom sa visine direktno na odeljenje ortopedije ili neurohirurgije, jer može doći 
do propusta u dijagnostici teških povreda. Specijalista trauma hirurg trebalo bi da je dostupan bar u prvih $24 \mathrm{~h}$.

Greška je potceniti rizike kod srednje teške traume. Značajan je intenzivni monitoring ovakvih pacijenata i spremnost da budu primljeni/prevedeni u JIL (jedinicu intenzivnog lečenja).

Potrebno je što pre uzeti detaljnu anamnezu od pacijenta ili porodice o ranijim oboljenjima i terapiji (beta-blokatori, kardiotonici, antihipertenzivi, antikoagulansi, aspirin) $)^{5}$. Problem predstavlja povećana opasnost od krvarenja, naročito intrakranijalnog ${ }^{6}$ !

\section{Greške u zbrinjavanju pacijenta sa povredom glave}

Zatvorene i izolovane povrede glave obično ne izazivaju pad pritiska, osim u terminalnom stadijumu ili kod dece. Tada treba tražiti razlog hipotenzije ili u masivnom krvarenju ili u druženoj povredi kičmene moždine.

Klinički manje povrede glave (GCS 13-15) mogu biti udružene sa signifikantnim intrakranijalnim lezijama. Svi pacijenti sa GCS manjim od 15 i anamnestičkim podatkom o gubitku svesti ili amneziji trebalo bi da se upute na CT.

Razderine po glavi dosta krvare. Suturiranje bez prethodne radiografije je pogrešno.

- DIC i konvulzije su česte kod teških trauma. Neophodan je monitoring i profilaksa antikonvulzivima 7-10 dana. ALI...

Ne davati antikonvulzive profilaktički duže od 7 do 10 dana $^{7}$. Prolongirana profilaksa ne smanjuje rizik od nastanka posttraumatske epilepsije.

I kod manjih povreda glave postoji velika verovatnoća nastanka intrakranijalnog krvarenja,pa ne treba izbegavati CT.

\section{Greške kod zbrinjavanja pacijenta sa povredom vrata}

Zaštita vratne kičme: meki okovratnik ne pruža nikakvu zaštitu vratne kičme, već je delimično štiti. Tokom transporta uvek primeniti imobilizaciju celog tela na tvrdim nosilima - ležaljki. Dijagnostika stanja vratne kičme nije neophodna, ako ima urgentnijih procedura, sve dok je vratna kičma sigurno imobilisana ${ }^{1,7}$.

\section{Protokol lečenja kod penetrantnih povreda vrata}

A. Prioriteti po stepenu hitnosti

1. Kontrola akutnog krvarenja (kompresija, zavoj, Folyev dren);

2. U slučaju akutnog krvarenja - ležeća pozicija (Trendelenburgov položaj) radi prevencije nastanka embolije;

3. Obezbediti vazdušne puteve;

4. Intravenska nadoknada tečnosti (ne uvoditi vensku liniju na strani povrede); 
U zavisnosti od kliničkog nalaza, sprovesti dalje dijagnostičke procedure: Doppler, endoskopiju, kontrastno snimanje, angiografiju (po listi indikacija).

\section{Greške u zbrinjavanju pacijenta sa povredom kičmene moždine}

Proširen medijastinum: pored rupture aorte misliti i na povredu obično torakalnog dela kičmenog stuba.

- Kod svih pacijenata sa znatnom palpatornom osetljivošću kičmenog stuba treba učiniti CT, čak i kada je radiografski nalaz uredan. ${ }^{8}$

Takođe treba uraditi i CT vratne kičme (C1-Th1) kod politraumatizovanih pacijenata sa nesigurnim podacima o mehanizmu povrede.

- Kvadriplegični pacijent na prijemu može biti lažno respiratorno stabilan. Brzo pogoršanje i akutna respiratorna insuficijencija mogu nastati izrazito brzo i obično je to pitanje vremena, pa treba razmotriti ranu intubaciju.

- Tvrda transportna nosila za imobilizaciju i zaštitu kičmenog stuba na kojima je pacijent transportovan vrlo su neudobna pa se pacijent nakon sprovedene radiografske dijagnostike premešta u postelju u JIL ili na operacioni sto., ${ }^{4,7}$

- Alarmantan je podatak forenzičkih izvora da se povrede vratne kičme previđaju tri puta češće nego povrede svih ostalih regiona kičmenog stuba!

\section{Greške u zbrinjavanju pacijenta sa vaskularnim povredama}

Postavljati u sedeći položaj pacijenta sa povredom vena. (postoji opasnost od embolije, pa zato pacijenta držati u ležećoj poziciji). ${ }^{9}$

- Uvođenje venske linije na istoj strani gde je i povreda vrata (mogućnost ekstravazacije infuzione tečnosti zbog lezija proksimalnih vena).

Postojanje perifernog pulsa ne isključuje postojanje signifikantne vaskularne povrede. Zato uvek uporediti nalaz sa nepovređenim ekstremitetom (palpacijom i Dopplerom).

- Angiogramom pri samo jednoj rtg ekspoziciji može se prevideti povreda arterija.

- Uvek posumnjati na povredu arterija kod zadnje dislokacije kolena.

- Kod teške ishemije ekstremiteta nastupile nakon traume ne treba odlagati niti kasniti sa operativnom intervencijom da bi se sačekao angiografski nalaz. Ukoliko je neophodno, angiografija se može učiniti i na operacionom stolu.

\section{Greške u zbrinjavanju pacijenata sa povredama grudnog koša}

- Spoljašnja masaža srca kod zastoja srca usled traumatskog krvarenja ili tamponade srca (metoda izbora kod reanimacije je torakotomija i direktna masaža srca). ${ }^{1.4 .7}$

- Zatvaranje zavojem ili sutura usisnih rana na grudnom košu pre uvođenja torakalnog drena (moguć nastanak pneumotoraksa. Ukoliko je neophodno plasiranje zavoja, tj. previjanje, aplikovati četvrtastu gazu pričvršćenu za kožu samo sa tri strane). 
Torakalni kapak: inicijalno, gasne analize mogu biti u granicama normale, ali stanje se može vrlo brzo pogoršati, pa je važno pratiti oksigenaciju oksimetrijom i gasnim analizama. Kod starije populacije poželjna je rana intubacija i pre CT nalaza.

- Kod tenzionog pneumotoraksa dijagnoza se postavlja kliničkim pregledom! Kašnjenje zbog radiološke potvrde dijagnoze može biti pogubno.

- Proširenje gornjeg dela mediastinuma nakon saobraćajnog udesa ili pada sa visine, pored rupture aorte može ukazivati i na povredu grudnog dela kičme.

- S druge strane, mnogi pacijenti sa rupturom torakalne aorte mogu imati normalan nalaz mediastinuma, pa je zato potrebno rutinski sprovoditi CT kod svih pacijenata kod kojih je mehanizam povređivanja saobraćajni udes ili pad sa visine. ${ }^{10}$

- Mnoge povrede dijafragme mogu biti asimptomatske a radiografija grudnog koša normalna. Za povrede leve strane, kao i prednje desne strane torakoabdominalne regije sprovesti rutinsku laparoskopiju bez obzira na klinički nalaz. ${ }^{7,10}$

- Tamponada srca: pacijent je obično vrlo uznemiren, a neiskusan hirurg takvo stanje može pogrešno tumačiti alkoholisanošću ili intoksikacijom drogama i opijatima.

Hemotoraks srednjeg obima može biti previđen na rtg snimcima u stojećem položaju.

Kada se razmatra povreda grudnog koša, obično se nema u vidu da prva radiografija „ne vidi” 30\% fraktura rebara bez dislokacije i kada je snimak korektan.

Na snimcima su često ,otsečena” gornja i/ili donja rebra, što vodi u dalje previđanje povreda (vratna kičma, dijafragma, abdomen).

Fisure sternuma se često previđaju jer se ne uradi profilni snimak. Povrede sternuma su sumnjive na druge teške povrede!

Kontuzija miokarda je često previđena povreda ako nije dovela do smrtnog ishoda na terenu. Javlja se najčešće zbog udarca volana ili zatezanja sigurnosnog pojasa. Ne mora postojati povreda sternuma! Zato je neophodno znati što više detalja o mehanizmu povrede. ${ }^{10,11}$

\section{Greške u zbrinjavanju pacijenta sa povredom abdomena i karlice}

Propuštanje da se uradi rektalni i vaginalni pregled kod povreda karlice može dovesti do previda teških povreda). Ne vršiti rutinski vaginalni pregled kod dece.

Negativan UZ nalaz ne isključuje signifikantne intraabdominalne povrede. Kod dijafragmalnih I retroperitonealnih povreda i perforacija šupljih organa on je često lažno negativan. ${ }^{12}$

Povrede dijafragme mogu biti asimptomatske a nalaz radiografije grudne duplje uredan. Zato je potrebno sprovesti rutinsku laparoskopiju kod svih pacijenata sa penetrantnom povredom leve ili prednje desne torakoabdominalne regije čak i u odsustvu simptoma. 
Tupe pankreatikoduodenalne povrede obično ne daju rane znake peritonita. U sumnjivim slučajevima potrebno je ponavljano sprovoditi CT (sa oralnim i i.v. kontrastom), kao i ispitivanje serum, amilaze i leukocitarne formule.

Perforacije šupljih organa izazvane tupim traumama često mogu biti previđene. Zato obratiti pažnju na skrivene znake na CT snimku (nerazjašnjeno prisustvo slobodne tečnosti, gasa, zadebljanje zida ili suženje lumena creva), kao i neobjašnjivu leukocitozu, i pogoršanje baznog deficita bez kliničke manifestacije. Uvek proveriti i revidirati CT nalaz uz iskusnog radiologa.

Odlaganje angiografije i embolizacije kod povreda karlice je nepotrebno i rizično. ${ }^{10}$ Preti značajan gubitak krvi i poremećaj koagulacije.

Procenjujući radiografiju karlice može se potceniti težina pelvične frakture, pa se preporučuje CT, naročito za multiple i nestabilne frakture.

\section{Deca, stariji pacijenti i trudnice-pacijenti sa posebnim potrebama u zbrinja- vanju trauma}

Deca

Kod dece do tri godine uzrasta, pa i nešto kasnije, treba imati u vidu anatomske i razvojne specifičnosti. Tako, na primer, zbog elastičnosti rebara ne mora postojati fraktura, što navodi na pogrešan zaključak da ne postoji ozbiljna povreda grudnog koša ${ }^{13}$; međutim, na mestu povrede može se nalaziti značajno kontuziono žarište na plućima, koje bi kod odraslih podrazumevalo čak i višestruku frakturu rebara.

Mogućnost komunikacije sa malom decom svedena je na minimum.

Uvek treba imati u vidu da su deca sklona brzom nastanku hipotermije.

\section{Stariji pacijenti}

Kod starih osoba postoji čitav niz zamki u dijagnostici, pa tako i mogućnosti previđanja povreda. Kod onih koji imaju terapiju beta-blokatorima ili im je ugrađena pace maker redukovana je tahikardija, kao reakcija na hipovolemiju. Uzimanje u obzir ove činjenice može sprečiti kobno tumačenje hemodinamske stabilnosti u svetlosti normalnog broja otkucaja u jedinici vremena. Takođe treba imati na umu da većina starijih osoba ima hipertenziju te da su ,normalne” vrednosti arterijske tenzije, zapravo, hipotenzija. ${ }^{4,14}$

\section{Trudnice}

Greška je potceniti gubitak krvi kod ,stabilnih” vitalnih parametara.U poodmakloj trudnoći gubitak od $1500 \mathrm{ml}$ krvi ne mora se manifestovati hipotenzijom.

Ne treba odlagati radiografiju ili CT zbog trudnoće kod traume koju je doživela trudnica. 
Ne treba potceniti gubitak fetusa kod relativno lake povrede majke., ${ }^{1,15}$

Ne sme se pokušavati spasti fetus na račun majke - najbolji tretman fetusa je reanimacija majke!

\section{Zaključak}

Pregled politraumatizovanog pacijenta prilikom prijema obično je skopčan sa nedostatkom vremena i sa presijom od strane drugih specijalista, porodice, medija... Ovakva situacija zahteva ne samo medicinsko znanje, već i radno iskustvo, hladnokrvnost i mogućnost odupiranja uticajima ljudi iz različitih oblasti i usredsređenosti isključivo na pacijenta i njegovo sveukupno stanje.

\section{Literatura}

1. Brooks A, Holroyd B, Riley B. (2004) Missed injury in major trauma patients. Injury 35: 407-410.

2. Janjua KJ, Sugrue M, Deane SA. (1998), Prospective evaluation of early missed injuries and the role of tertiary trauma survey. J Trauma 44: 1000-1006.

3. Soundappan SV, Holland AJ, Cass DT. (2004), Role of an extended tertiary survey in detecting missed injuries in children. J Trauma 57: 114-118.

4. Enderson BL, Reath DB, Meadors J, et al. (1990). The tertiary trauma survey: a prospective study of missed injury. J Trauma 30: 666-669.

5. American College of Surgeons (1997). Committee on trauma: advanced trauma life support, 6th edn. American College of Surgeons, Chicago.

6. Williams BG, Hlaing, Aaland MO. Ten-year retrospective study of delayed diagnosis of injury in pediatric trauma patients at a level II trauma center.

7. Aaland MO, Smith MD. 1996. Delayed diagnosis in a rural trauma center. Surgery 120: 774-779.

8. Snoek, A, Dekker, M, Lagrand, T. A clinical decision model identifies patients at risk for delayed diagnosed injuries after high-energy trauma. Eur J Emerg Med 2013; 20: $167-172$.

9. Giannakopoulos, GF, Saltzherr, TP, Beenen, LFM. Missed injuries during the initial assessment in a cohort of 1124 level-1 trauma patients. Injury 2012; 43: 1517-1521.

10. Stephan PJ, McCarley MC, O'Keefe GE, Minei JP. 2002. 23 hour observation solely for identification of missed injuries after trauma: is it justified? J Trauma-Injury Infect Crit Care 53(5): 895-900.

11. Houshian S, Larsen MS, Holm C. 2002. Missed injuries in a level 1 trauma center. J Trauma 52(4): 715-719.

12. Keijzers, GB, Campbell, D, Hooper, J. A prospective evaluation of missed injuries in trauma patients, before and after formalising the trauma tertiary survey. World J Surg 2014; 38: 222-232. 
13. Born CT, Ross SE, Iannacone WM, Schwab W, DeLong WG. 1989. Delayed identification of skeletal injury in multi-system trauma: the missed fracture. J Trauma 29(12): 1643-1646.

14. Adam Brooksa, Ben Holroydb, Bernard Rileyc. Missed injury in major trauma patients. Injury, Vol. 35, Iss. 4, 2004; 407-410

15. Zamboni, C, Yonamine, AM, Faria, CE. Tertiary survey in trauma patients: Avoiding neglected injuries. Injury 2014; 45 (Suppl. 5): S14-S17. 